\title{
NALLD JOURNAL INDEX 1980-1984
}

\author{
Jackie Tanner
}

\section{ALPHABETICALLY BY AUTHOR AND TITLE VOLUME XIV THROUGH VOLUME XVII}

Achievement Awards:

Thomas R. Goldsworthy: V.\#16-1

LLA of Japan: V. 16-1

ACTFL Proficiency Workshops: V.\#17-1

Alatis, James $\mathrm{E}$.

"The Future of Foreign Language Teaching in the U.S."

V. $17 \# 1$

Albertson, Kathleen

"Teaching Pronunciation with Visual Feedback"

V. $17 \# 1$

Aleman-Centano, Josefina $R$.

"Computerized Audio-Visual Instructional Sequences"

V. $17 \# 3-4$

Arkwright, Thomas D.

"Issues \& Realities in Computer Based Instruction:

Bibliography"

V. $17 \# 3-4$

Association of French School of Quebec

V. $14 \# 3-4$

Behnke, Ralph

"Effects of Rate-Altered Lectures on the Acquisition of True Knowledge"

V. $15 \# 1$

Beatty, Michael

"Effects of Rate-Altered Lectures on the Acquisition of True Knowledge"

V. $15 \# 1$ 
"Better Listening Skills, A Video Review"

Joyce Hutchings

V. 17 \#3-4

Betti, Franco

Teatro, Prosa, Poesia. A Second Year Anthology.

A Tape Review

V. $17 \# 3-4$

Burke, Anne (Leidy, Howard, \& Merkel)

"Using Computer Assisted Instruction in an ESL Language Program"

V. $15 \# 1$

Chinn, Phillip C. (Hardman \& Drew)

"Intentional/Incidental Learning Capabilities of Retarded Children"

V. $15 \# 2$

Cole, Bennett

"The Learning Lab Director as Public Relations Person"

V. 14 \#1

"Computers and Foreign Language Instruction" John Russell

V. $16 \# 3-4$

"Computerized A.V. Instructional Sequences" Josefina R. Aleman-Centano

V. $17 \# 3-4$

"Constructing an Inexpensive Slide Copier"

Mark Seng

V. $14 \# 1$

Crawford, William

"Follow Me to San Francisco, A Videotape Review"

V. $17 \# 3-4$

Davidson, Craig (Maute)

"Mission Consolidated Independent School District Computer Science Instruction Program"

V. $16 \# 3-4$

Davies, Norman

"Foreign/Second Language Education and Technology in the Future"

V. $16 \# 3-4$ 
"Dial Access Retrieval"

F. Knowlton Utley

V. $17 \# 2$

Dick, John

"We Speak Russian, A Video Review"

V. $17 \# 3-4$

"Difficulty of Intercultural Communications between Americans and Japanese, The"

Kenji Kitao

V. 14 \#2

Drew, Clifford J. (Hardman \& Chinn)

"International/Incidental Learning Capabilities of Retarded Children"

V. $15 \# 2$

Driscoll, John

"Research Trends in Rate Controlled Speech"

V. $15 \# 2$

"Educational Implications of Cerebral Lateralization: A Neurosociological Perspective"

Kaplan, Ten Housten, \& Wogan

V. 14 \#2

"Effects of Rate-Altered Lectures on the Acquisition of True Knowledge"

Ralph Behnke \& Michael Beatty

V. $15 \# 1$

"Evaluation of Oral/Aural Testing in Modern Foreign Languages at Boston University, An"

Gail Kung \& Diane Nadeau

V. $16 \# 1$

FLEAT Committee Members

V. $15 \# 3-4$

FLEAT

"Expectation of the International Conference"

V. 15 \#3-4

"A Guide to the use of the List of FLEAT Participants"

V. $15 \# 3-4$ 
Joint statement by Language Lab Association of Japan (LLA) and the National Association of Learning Laboratories (NALLD) Regarding International Cooperation in the Use of Technology for Foreign and Second Language Learning V. 16 \#3-4

Program

V. $15 \# 3-4$

"Tokyo - What To Do and How To Do It"

V. $15 \# 3-4$

"Follow Me to San Francisco, A Video Review"

Wm. Crawford

V. $17 \# 3-4$

"Foreign/Second Language Education and Technology in the Future" Norman Davies

V. $16 \# 3-4$

"Future of Foreign Language Teaching in the U.S., The" James E. Alatis

V. $17 \# 1$

Gillespie, Juanita

"Striking the " $R$ ": Demythologizing the Computer Revolution" V. $17 \# 3-4$

"Cold Suit Connection: A "Real" Listening Comprehension, The" Nancy N. Hildebrandt

V. $14 \# 2$

Griffin, Suzanne M.

"Video Studios: The Language Labs for the 1980's"

V. $15 \# 2$

Hardman, Michael L. (Drew \& Chinn)

"Intentional/Incidental Learning Capabilities of Retarded Children"

V. $15 \# 2$

Hildebrandt, Nancy Nakanishi

"The Cold Suit Connection: A "Real" Listening Comprehension" V. 14 \#2

"Home Made Package for Use in the Language Lab, A"

Roger Kenner \& Griff Richards

V. $15 \# 1$ 
"How to Organize a Tape Take-Home Service"

Michael Kessler

V. 14 \#2

Howard, Martin (Leidy, Merkel, Burke)

"Using Computer Assisted Instruction in an ESL Language Program"

V. $15 \# 1$

Hutchings, Joyce

"Better Listenings Skills, A Video Review"

V. $17 \# 3-4$

"International/Incidental Learning Capabilities of Retarded Children" Michael L. Hardman, Clifford J. Drew, \& Phillip C. Chinn

V. 15 \#2

IALL

Constitution of the International Association for Learning Laboratories

V. 16 \#3-4

"Issues \& Realities in Computer Based Instruction: Bibliography"

Thomas Arkwright

V. $17 \# 3-4$

Japan LLA

V. $15 \# 3-4$

Johnson. Barbara A.

"Learning Laboratory Planner from Tandberg, A Review"

V. $17 \# 3-4$

Joint National Committee for Languages (JNCL)

V. 16 \#2

V. $17 \# 1$

V. $17 \# 2$

Kanaba, Steve

"The Roles of U-Matic vs. VHS: Consideration for Educational

Technologists"

V. 14 \#3-4

Kaplan, Charles (Ten Housten \& Wogan)

"Educational Implications of Cerebral Lateralization: A Neurosociological Perspective"

V. 14 \#2 
Kenner, Roger

"Report on the Concordia Colloquium on Language Laboratories"

V. $15 \# 1$

"A Home Made Package for Use in the Language Lab"

V. $16 \# 2$

Kessler, Michael

"How to Organize a Tape Take-Home Service"

V. 14 \#2

Kitao, Kenji

"The Difficulty of Intercultural Communication Between Americans and Japanese"

V. $14 \# 2$

"The Test of American Culture"

V. 15 \#2

King, Gail \& Nadeau

"An Evaluation of Oral/Aural Testing in MFL at Boston University"

V. $16 \# 1$

Lally, Dale

Editor's Corner

Conference Updates

NALLD Notes

"Language-By-Radio In Sub-Saharan Africa: Four Case Studies"

Edmun Richmond

V. 16 \#2

"Language Laboratory, The"

Joseph H. Sheehan

V. $15 \# 1$

Language Laboratory Association of Japan

V. 15 \#3-4

Lawrason, Robin

Profiles

V. 16 \#2

Lawrason, Robin E. \& Carlos Lugo

"Student Attitudes Towards Language Lab Facilities at Temple University"

V. 14 \#1 
"Learning Lab Director as P.R. Person"

Bennett Cole

V. 14 \#1

Learning Laboratory Planner from Tandberg, A Review

Barbara Johnson

V. $17 \# 3-4$

Leidy, Judy (Merkel, Burke \& Howard)

"Using Computer Assisted Instruction in an ESL Language Program"

V. $15 \# 1$

Lugo, Carlos \& Lawrason

"Student Attitudes towards Language Lab Facilities at Temple University"

V. 14 \#1

MacGregor, Karen

"At Last (whew)! Off-Air Copying Guidelines", Article Review

V. 16 \#2

Maute, Harry (Davidson)

"Mission Consolidation Independent School District Computer

Science Instructional Program"

V. $16 \# 3-4$

Merkel, Ann (Leidy, Burke \& Howard)

"Using Computer Assisted Instruction in an ESL Language Program"

V. $15 \# 1$

"Mission Consolidation Independent School District Computer Science Instructional Program"

Craig Davidson \& Harry Maute

V. 16 \#3-4

NALLD Journal Index 1968-1979

Jackie Tanner

V. 14 \#3-4

NALLD Learning Laboratory Directors

V. $15 \# 3-4$

NALLD Membership List

V. 14 \#3-4 
NALLD News

V. $14 \# 1$

V. 14 \#2

V. 14 \#3-4

NALLD President Message

Joseph $\mathrm{H}$. Sherman

V. 16 \#1

NALLD Profiles

Robin Lawrason at Temple

V. 16 \#2

NCFLIS

"National Council on Foreign Languages \& International

Studies"

V. 14 \#3-4

Nadeau, Diane (King)

"On Evaluating Oral/Aural Testing in MFL at Boston University"

V. $16 \# 1$

Newton, Terry

Review: Developing Listening Comprehension for ESL Students:

The Kingdom of Kochen

V. $14 \# 1$

"Off the Air"

V. $14 \# 1$

V. $14 \# 2$

V. 14 \#3-4

V. $15 \# 1$

V. $15 \# 2$

V. $15 \# 3-4$

Polly, Lyle, R.

"Three Fifteen-Minute Activities for Beginning Foreign Language Students: Reading, Writing, and Arithmetic"

V. $14 \# 1$

"Quick Fix on Sony CCP 13A Duplicators"

V. $17 \# 1$

"Radio Rurale: Education and Information For an Illiterate People" Edmun B. Richmond

V. $15 \# 1$ 
"Report on the Concordia Colloquium on Language Laboratories" Roger Kenner

V. $16 \# 2$

"Research Trends in Rate-Controlled Speech" John Driscoll

V. 15 \#2

Reviews

Video: Better Listening Skills

Follow Me to San Francisco

We Speak Russian

Audio: Teatro, Prosa, Poesia

Richards, Griff

"A Home Made Package for Use in the Language Lab"

V. 15 \#1

Richmond, Edmun

"Radio Rurale: Education \& Information for an Illiterate People"

V. 15 \#1

"Language by Radio in Sub-Saharan Africa" Four Case Studies

V. $16 \# 2$

"Off the Air"

V. $14 \# 1$

V. 14 \#2

V. $14 \# 3-4$

V. $15 \# 1$

V. $15 \# 2$

Rivers, Wilga $M$.

"Understanding the Learner in the Language Laboratory"

V. $16 \# 2$

"Roles of U-Matic vs. VHS: Consideration for Education Technologists, The"

Steve Kanaba

V. 14 \#3-4

Russell, John

"Computers \& Foreign Language Instruction"

V. $16 \# 3-4$

Seng, Mark

"Constructing an Inexpensive Slide Copier"

V. $14 \# 1$ 


\section{BEL AIR SOFTWARE INC. \\ PO BOX 1045, BEL AIR MD 21014 \\ 301 879-8784}

We feature quality foreign language software at a discount, but we can supply most of your computer needs in other fields as well. Call or write for our prices on any software or hardware not listed.

FRENCH List Ours

Cherchez la différence $24.95 \quad 19.95$

French Achievement I $49.95 \quad 39.95$

French Achievement II $49.95 \quad 39.95$

French Clock $\quad 49.95 \quad 39.95$

French Hangman $29.95 \quad 23.95$

French-Eng. Vocab Bldr. 30.0023 .95

$\begin{array}{lll}\text { Mystery House (VF) } \quad 24.95 & 19.95\end{array}$

Perspectives françaises 10 disk set each disk

350.00280 .00

$39.95 \quad 31.95$

GERMAN

Apfeideutsch

192.00159 .95

German-Eng. Vocab B1dr. 30.0023 .95

German-Russian Hangman 29.9523 .95 SPANISH

Alicia

$29.95 \quad 23.95$

Episodios elementales $\quad 99.00 \quad 89.00$

Episodios auth. system

Spanish Clock

53.00

Spanish Concluesion

$49.95 \quad 39.95$

Spanish-Eng. Vocab Bldr $30.00 \quad 23.95$

Spanish Hangman

Spanish Numbers

CHINESE

Chinese Lessons

RUSSIAN

$29.95 \quad 23.95$

$49.95 \quad 39.95$

$34.95 \quad 27.95$

German-Russian Hangman

Russian Disk

LATIN

$29.95 \quad 23.95$

$29.95 \quad 23.95$

Latin Hangman

$29.95 \quad 23.95$ 


\section{Summer '84}

\section{THE TECHNOLOGY OF LANGUAGE TRAINING}

AND USE

Mon, July 30 - Sat, Aug 11

Under the auspices of the National Resource Center for Translation \& Interpretation

Seminar Director Jacquelyn Tanner

Director of Language Learning Technology

Primarily for persons from teaching institutions and conference centers.

\section{PROGRAM TOPICS}

Simultaneous Equipment * Sample Budgets Audio Visual Equipment * Satellite Systems Word Processing Units * Language Labs

For further information and a program brochure, please return the attached form.

The Technology of Language Training \& Use School for Summer \& Continuing Education 306 Intercultural Center

Georgetown University

Washington, D.C. 20057

Name:

Address: 
"Satellites: A Peek over the Horizon"

Dale Lally

V. 14 \#2

Sheehan, Joseph

"President's Message"

V. $16 \# 1$

Sinatra, Richard

"Visual Composition \& Language Development"

V. $15 \# 2$

Smith, Philip D.

"A Study of the Effect of Slowed Speech on Listening Comprehension of French"

V. $14 \# 3-4$

Spangehl, Stephen

Reviews:

"Shooting Slides for Television"

V. $16 \# 2$

"For The Record"

V. 16 \#2

"Dusting off your VCR - Why Educators are Taking a Second Look at Videocassette Recorders"

V. 16 \#2

"Making the Best Budgeting and Production Trade-Offs"

V. 16 \#2

"Primer for Purchasing Software"

V. 16 \#2

"Study Carrels: From the Ancient Greeks to Interactive Video"

V. 16 \#2

"Large-Screen Video Projection Systems"

V. 16 \#2

St. Clair, Robert

"Technology and Mediated Instruction: An Interdisciplinary Essay"

V. 14 \#1

Reviews:

Origins of Western Literacy

V. 15 \#2

Test Lessons in Reading Figurative Language

V. $15 \# 2$

Interaction of Media, Cognition, and Learning

V. $14 \# 1$ 
The new literacy: the language of film and television

V. $15 \# 2$

Primer of Visual Literacy

"Striking the " $R$ ": Demythologizing the Computer Revolution" Juanita Gillespie

V. $17 \# 3-4$

"A Study of the Effect of "Slowed Speech on Listening Comprehension of French"

Philip D. Smith, Jr.

V. $14 \# 3-4$

Tanner, Jackie

A Video Review

V. $17 \# 3-4$

"Teaching Pronunciation with Visual Feedback"

Kathleen Albertson

V. $17 \# 1$

Teatro, Prosa, Poesia: A Second Year Anthology, Tape Review Franco Betti

V. $17 \# 3-4$

Temple University Media Learning Center, NALLD Profiles V. $16 \# 2$

TenHouten, Warren D. (Kaplan, \& Wogan)

"Educational Implications of Cerebral Lateralization: A Neurosociological Perspective"

V. $14 \# 2$

"Three Fifteen-Minute Activities for Beginning Foreign Language Students: Reading, Writing \& Arithmetic"

Lyle R. Polly

V. 14 \#1

Trans-European Student Programs (TESP)

V. $16 \# 1$

"Test of American Culture, The"

Kenji Kitao, Doshisha University

V. 15 \#2

"Understanding the Learner in the Language Laboratory"

Wilga M. Rivers

V. $16 \# 2$ 
"Using Computer Assisted Instruction in an ESL Language Program" Judy Leidy, Anne Merkel, Ann Burke, Marlin Howard

V. $15 \# 1$

Utley, F. Knowlton

"Dial Access Retrieval"

V. $17 \# 2$

"Video Studios: The Language Labs for the 1980's"

Suzanne M. Griffin

V. $15 \# 2$

"Visual Composition and Language Development"

Richard Sinatra

V. $15 \# 2$

"We Speak Russian, Videotape Review"

John Dick

V. $17 \# 3-4$

West European Center

V. $17 \# 3-4$

Wogan, Michael

"Educational Implication of Central Lateralization:

A Neurosociological Perspective"

V. $14 \# 2$

Wood, Richard

"Off the Air"

V. $16 \# 3-4$ 